\title{
Determinan Ekspor Teh Indonesia ke Amerika Serikat
}

\author{
Grasella Olivia Br Tarigan $^{1 *}$, M. Syurya Hidayat ${ }^{2}$, Nurhayani ${ }^{3}$ \\ ${ }^{1,2,3}$ Prodi Ekonomi Pembangunan, Fakultas Ekonomi dan Bisnis, Universitas Jambi

\begin{tabular}{|c|c|c|c|}
\hline Diterima: 25-11-2021 & Direvisi: 14-12-2021 & Disetujui: 20-12-2021 & Dipublikasi: 31-12-2021 \\
\hline
\end{tabular}

\begin{abstract}
This study aims to analyze the effect of United States GDP, Rupiah exchange rate against the US Dollar, international tea prices, and the United States per capita tea consumption on Indonesian tea exports to the United States. The data used is secondary data with 18 years (2000-2017). Data were analyzed using a multiple linear regression model. The results showed that United States GDP, international tea prices, and the United States per capita tea consumption significantly affect Indonesian tea exports to the United States. Meanwhile, the Rupiah exchange rate against the United States Dollar does not affect Indonesian tea exports to the United States.
\end{abstract}

Keywords: GDP, exchange rate, price, consumption, export

\begin{abstract}
Abstrak
Penelitian ini bertujuan untuk menganalisis pengaruh GDP Amerika Serikat, nilai tukar Rupiah terhadap Dollar AS, Harga teh internasional, dan konsumsi teh perkapita Amerika Serikat terhadap ekspor teh Indonesia ke Amerika Serikat . Data yang digunakan adalah data sekunder dengan rentang waktu 18 tahun (2000-2017). Data dianalisis menggunakan model regresi linear berganda. Hasil penelitian memperlihatkan bahwa GDP Amerika Serikat, harga teh internasional, dan konsumsi teh perkapita Amerika Serikat berpengaruh signifikan terhadap ekspor teh Indonesia ke Amerika Serikat. Sedangkan kurs Rupiah terhadap Dollar Amerika Serikat tidak berpengaruh terhadap ekspor teh Indonesia ke Amerika Serikat.
\end{abstract}

Kata kunci: GDP, nilai tukar, harga, konsumsi, ekspor

\section{Pendahuluan}

Ekspor Indonesia merupakan kegiatan perdagangan yang bertujuan untuk mengirim barang dan jasa dari batas wilayah Indonesia keluar negeri, melalui prosedur dan tata cara ekspor yang telah diatur oleh pemerintah Indonesia. Ekspor Indonesia terbagi menjadi dua jenis yaitu ekspor migas dan ekspor nonmigas. Sektor migas merupakan sektor yang diperoleh dari penerimaan ekspor minyak mentah baik dari minyak bumi maupun gas alam, sedangkan ekspor nonmigas diperoleh dari penerimaan ekspor tiga sektor yaitu: sektor pertanian, sektor industri, sektor pertambangan dan lainnya.

Sektor pertanian merupakan salah satu sektor yang memegang peran cukup besar dalam perekonomian Indonesia, hal tersebut dapat dilihat dari kontribusinya terhadap Produk Domestik Bruto (PDB) Indonesia pada tahun 2017 yaitu sekitar 55\%. Perkebunan sebagai salah satu sub sektor pertanian juga memegang peran cukup penting dalam perekonomian, meskipun kontribusi nya terhadap PDB belum terlalu besar namun subsektor ini merupakan penyedia bahan baku bagi sektor industri, penyerap tenaga kerja, dan penghasil devisa negara.

\footnotetext{
* Penulis korespondensi

Email: grasellatarigan@gmail.com
} 
Komoditi teh merupakan salah satu komoditi unggulan dalam subsektor perkebunan Indonesia dan juga merupakan komoditi unggulan ekspor Indonesia, hal ini dikarenakan teh tidak hanya mempunyai peluang pasar yang baik di dalam negeri tetapi juga di luar negeri. Indonesia sendiri merupakan negara pengekspor teh kelima di dunia setelah Sri Lanka, Kenya, Tiongkok dan India.

Salah satu negara tujuan utama ekspor teh Indonesia adalah Amerika Serikat. Amerika Serikat dikenal sebagai negara pengkonsumsi teh terbesar di dunia. Hal tersebut menjadikan Amerika Serikat sebagai pangsa pasar potensial bagi Indonesia untuk mengekspor teh. Perkembangan nilai ekspor teh Indonesia ke Amerika Serikat diberikan pada Tabel 1.

Tabel 1. Nilai ekspor teh Indonesia ke Amerika Serikat periode 2013-2017

\begin{tabular}{cc}
\hline Tahun & Nilai Ekspor Teh (USD) \\
\hline 2014 & 9.281 .900 \\
2014 & 7.613 .800 \\
2015 & 5.685 .600 \\
2016 & 6.123 .760 \\
2017 & 6.721 .450 \\
\hline
\end{tabular}

Sumber: Kementrian Keuangan-Direktorat Jenderal Bea dan Cukai, 2018

Berdasarkan Tabel 1 dapat dilihat bahwa perkembangan nilai ekspor teh Indonesia ke Amerika Serikat terus mengalami fluktuasi. Dimana pada tahun 2013 sebesar 9.281.900 USD. Pada tahun 2014 dan 2015 nilai nya mengalami penurunan yang masing-masing sebesar 7.613.800 USD pada tahun 2014 dan 5.685.600 USD pada tahun 2015. Pada tahun 2016, nilai ekspor teh Indonesia ke Amerika Serikat mengalami peningkatan dari tahun sebelumnya menjadi 6.123.760 USD. Dan pada tahun 2017, nilai ekspor teh Indonesia ke Amerika Serikat kembali mengalami peningkatan dimana nilainya menjadi 6.721.450 USD. Ketidakstabilan ekspor teh Indonesia tersebut diduga dipengaruhi oleh beberapa faktor seperti GDP Amerika Serikat, kurs Rupiah terhadap Dollar Amerika Serikat, harga teh internasional, dan konsumsi teh perkapita Amerika Serikat. Perubahan-perubahan tersebut tentu akan berdampak pada perekonomian Indonesia terutama akan berpengaruh terhadap devisa negara.

\section{Metode}

Penelitian ini menggunakan data sekunder yang merupakan data berkala (time series) dari tahun 2000-2017. Metode analisis yang digunakan adalah metode analisis deskriptif dan kuantitatif yang bertujuan untuk mendapatkan gambaran mengenai hubungan dan pengaruh antara variabel bebas terhadap variabel terikat. Pendekatan kuantitatif menghasilkan data riil berupa angka dan dapat diukur dengan pasti. Analisis data yang digunakan dalam penelitian ini adalah analisis regresi linier dengan melihat pengaruh GDP Amerika Serikat, kurs Rupiah terhadap Dollar Amerika Serikat, harga teh internasional dan konsumsi teh perkapita Amerika Serikat terhadap ekspor teh Indonesia ke Amerika Serikat. Regresi adalah suatu proses memperkirakan secara sistematis tentang apa yang paling mungkin terjadi di masa yang akan datang berdasarkan informasi masa lalu dan sekarang yang dimiliki agar kesalahannya dapat diperkecil.

$$
\begin{array}{ll}
\text { NET }=\mathrm{a}+\beta_{1} \mathrm{GDP}_{\mathrm{AS}}+\beta_{2} \mathrm{KR}+\beta_{3} \mathrm{HTI}++\beta_{4} \mathrm{KT}+\mathrm{e} \\
\text { Keterangan: } & \\
\text { NET } & : \text { Ekspor Teh Indonesia ke AS } \\
\mathrm{GDP}_{\mathrm{AS}} & : \text { Pendapatan Nasional AS } \\
\mathrm{KR} & : \text { Kurs Rupiah/ Dollar AS } \\
\mathrm{HTI} & : \text { Harga Teh Internasional }
\end{array}
$$




$\begin{array}{ll}\text { HKI } & : \text { Konsumsi Teh Perkapita Amerika Serikat } \\ \beta_{1}, \beta_{2}, \beta_{3} & : \text { Koefisien Elastisitas } \\ \mathrm{a} & : \text { Konstanta } \\ \mathrm{e} & : \text { Standar Eror }\end{array}$

\section{Hasil dan Pembahasan}

\section{Uji Asumsi Klasik}

\section{Uji Multikolinearitas}

Multikolineritas merupakan salah satu model asumi klasik yang melihat hubungan antar sesama variabel bebas. Jika nilai variance influence factor (VIF) di bawah 10 maka model bebas dari gejala multikolineritas.

Tabel 2. Hasil uji multikolinearitas

\begin{tabular}{cccc}
\hline \hline Variable & $\begin{array}{c}\text { Coefficient } \\
\text { Variance }\end{array}$ & $\begin{array}{c}\text { Uncentered } \\
\text { VIF }\end{array}$ & $\begin{array}{c}\text { Centered } \\
\text { VIF }\end{array}$ \\
\hline \hline C & $3.11 \mathrm{E}+12$ & 44.06738 & NA \\
GDP $_{\text {AS }}$ & 40832.88 & 127.9170 & 4.267637 \\
KR & 15448.87 & 22.22252 & 1.711050 \\
HTI & 1973739. & 70.71052 & 2.392706 \\
KT & $2.44 \mathrm{E}+12$ & 112.0118 & 3.137812 \\
\hline \hline
\end{tabular}

Sumber: Data diolah, 2019

Berdasarkan data diatas, diketahui bahwa center VIF dari masing-masing variabel dibawah 10, artinya semua variabel tidak terindikasi gejala multikolineritas.

\section{Uji Heterokedastisitas}

Uji heterokedastisitas digunakan untuk mengetahui ada atau tidaknya penyimpangan asumsi klasik. Pengujian heterokedastisitas untuk melihat ketidaksamaan varian dari residual untuk semua pengamatan pada model regresi. Persyaratan yang harus dipenuhi adalah probabilitas dari setiap variabel tidak signifikan agar gejala heterokedastisitas tidak terjadi. Berikut hasil uji heterokedastisitas.

Tabel 3. Hasil uji heterokedastisitas

\begin{tabular}{llll}
\hline F-statistic & 0.480228 & Prob. F(14,3) & 0.8514 \\
Obs*R-squared & 12.44627 & Prob. Chi-Square(14) & 0.5705 \\
Scaled explained SS & 5.597624 & Prob. Chi-Square(14) & 0.9756 \\
\hline
\end{tabular}

Sumber: Data diolah, 2019

Berdasarkan hasil data yang telah di uji menggunakan Uji White, dapat diketahui $\mathrm{p}$ Value yang ditunjuk dengan nilai prob.Chi-Square(14) pada Obs*R-squared sebesar 0.5705. Dengan nilai $\mathrm{p}$ Value $0.9756>0,05$ maka tidak ada gejala heterokedastisitas atau model bebas dari gejala heterokedastisitas.

\section{Uji Autokorelasi}

Uji autokorelasi adalah sebuah analisis yang dilakukan untuk mengetahui adakah korelasi variabel yang ada di dalam model prediksi dengan perubahan waktu. Untuk mengetahui ada atau tidaknya gejala autokorelasi maka digunakan metode Breusch-Godfrey atau yang disebut Uji Lagrange Multiplier, dimana jika probabilitas lebih besar dari $\propto 0,05$ maka tidak ada gejala autokorelasi. Berikut hasil uji autokorelasi. 
Tabel 4. Hasil Uji Autokorelasi

\begin{tabular}{clcc}
\hline F-statistic & 0.155378 & Prob. F(2,11) & 0.8579 \\
Obs*R-squared & 0.494540 & Prob. Chi-Square(2) & 0.7809 \\
\hline
\end{tabular}

Berdasarkan hasil pengujian LM dapat dilihat bahwa nilai Prob.Chi-Square(2) yang merupakan $p$ value dari uji Breusch-Godfrey Serial Correlation LM Test, yaitu $0.7809>0,05$ $(\propto 5 \%)$, yang artinya tidak ada gejala autokoelasi.

\section{Uji Normalitas}

Uji normalitas adalah sebuah uji yang dilakukan dengan tujuan untuk melihat sebaran data pada sebuah kelompok data atau variabel, apakah sebaran tersebut terdistribusi dengan normal atau tidak. Pengujian ini dapat dilakukan dengan menggunakan Jarque-Bera Test. Apabila prob.JB hitung lebih besar dari $\propto 0,05$ maka dapat disimpulkan bahwa residual terdistribusi normal.

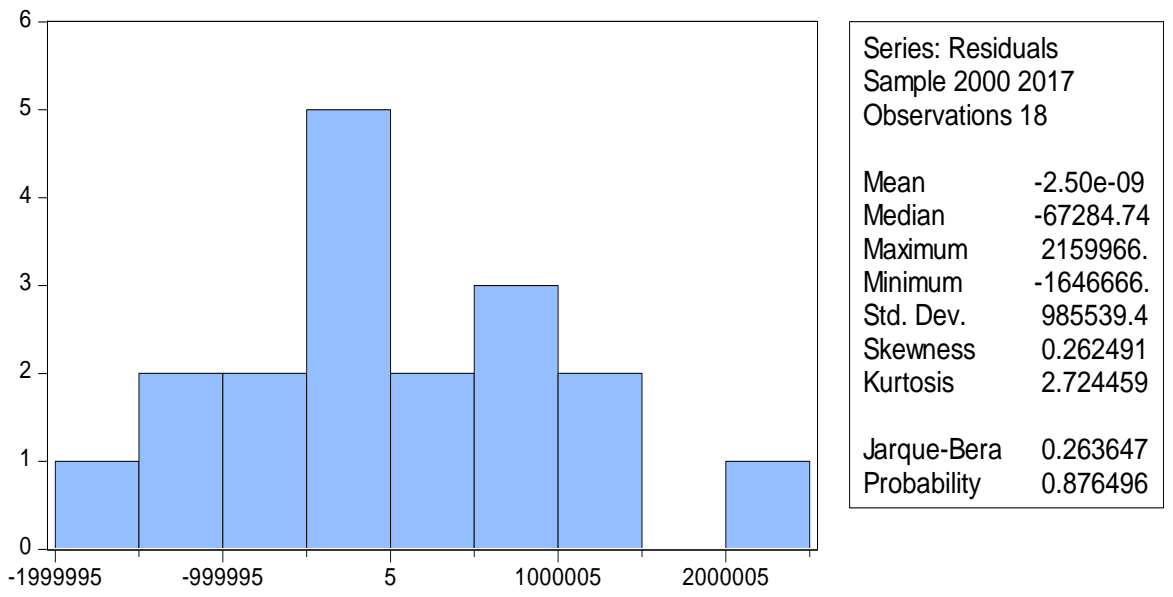

Gambar 1. Hasil uji normalitas

Sumber: Data diolah, 2019

Berdasarkan data diatas, dapat dilihat bahwa nilai Prob. Jarque-Bera hitung sebesar 0,876496>0,05 maka dapat disimpulkan bahwa residual terdistribusi normal dan artinya asumsi klasik tentang kenormalan telah terpenuhi.

\section{Uji Hipotesis}

Berdasarkan tujuan dari hasil penelitian diatas, maka dengan menggunakan analisis regresi linear berganda variabel harus diuji dengan pengujian statistik dan akan ditemukan model dari hubungan variabel dependen dan variabel independen.

\section{Pengujian Koefisien Regresi Secara Bersama-sama (Uji-F)}

Uji F merupakan uji yang digunakan untuk mengetahui apakah semua variabel independen (GDP Amerika Serikat, nilai tukar Rupiah terhadap Dollar AS, harga teh dipasar internasional, dan konsumsi teh perkapita Amerika Serikat) berpengaruh signifikan terhadap ekspor teh Indonesia ke Amerika Serikat.

Hasil yang diperoleh untuk F-hitung adalah sebesar 20.40465 dengan tingkat keyakinan 95\% $(\propto=0,05)$ diperoleh nilai dari F-tabelnya sebesar 3,18. Hasil regresi menunjukkan F-hitung > F-tabel yaitu $20.40465>3,18$ maka H0 ditolak dan H1 diterima yang artinya secara bersama-sama variabel GDP AS, nilai tukar Rupiah terhadap Dollar AS, harga teh internasional, dan konsumsi teh perkapita Amerika Serikat berpengaruh signifikan terhadap ekspor teh Indonesia ke Amerika Serikat. 


\section{Analisis Koefisien Determinan $\left(\boldsymbol{R}^{2}\right)$}

Koefisien determinasi digunakan untuk melihat seberapa besar pengaruh variabel bebas tehadap variabel terikat. Berdasarkan perhitungan statistik yang terdapat dalam tabel 5.6, diperoleh besarnya koefisien determinan $\left(\mathrm{R}^{2}\right)$ sebesar 0.862606 . Hal menunjukkan bahwa variabel independen (GDP Amerika Serikat, kurs Rupiah terhadap Dollar America Serikat, harga teh internasional, dan konsumsi teh perkapita Amerika Serikat) memberikan pengaruh terhadap perubahan nilai variabel dependen (ekspor teh Indonesia ke Amerika Serikat) sebesar 86,26 persen, sedangkan sisanya 13,74 persen dipengaruhi oleh variabel lain yang tidak termasuk ke dalam penelitian ini.

\section{Pengujian Koefisien Regresi Parsial (Uji-t)}

Uji-t dilakukan untuk melihat besarnya pengaruh dari setiap variabel independen terhadap variabel dependen. Nilai dari pengujian hipotesis terhadap koefisien secara parsial ditentukan dengan menggunakan tabel distribusi normal dengan tingkat signifikan $(\propto=0,05)$ dengan tingkat kepercayaan 95\% dan dengan derajat kebebasan $(\mathrm{df}=18-5=13)$, diperoleh $\mathrm{t}$ tabel sebesar 1,77.

Pada variabel GDP Amerika Serikat diketahui nilai t-hitungnya sebesar 2.550479 dan t-tabel sebesar 1,77. Dengan melihat perbandingan besarnya t-hitung dan t-tabel maka dapat diketahui bahwa t-hitung > t-tabel $(2.550479>1,77)$ dengan demikian $\mathrm{H}_{0}$ ditolak dan $\mathrm{H}_{1}$ diterima. Hal tersebut dapat diartikan bahwa GDP Amerika Serikat berpengaruh signifikan terhadap ekspor teh Indonesia ke Amerika Serikat.

Nilai t-hitung variabel nilai tukar Rupiah terhadap Dollar AS sebesar 1.059400 dan ttabel sebesar 1,77. Nilai t-hitung < t-tabel $(1.059400<1,77)$ dengan demikian $\mathrm{H}_{0}$ diterima dan $\mathrm{H}_{1}$ ditolak. Hal ini berarti bahwa nilai tukar Rupiah terhadap Dollar Amerika Serikat tidak berpengaruh terhadap ekspor teh Indonesia ke Amerika Serikat.

Nilai t-hitung untuk harga teh internasional sebesar 5.650784. Dengan demikian thitung > t-tabel $(1,77) . \mathrm{H}_{0}$ ditolak dan $\mathrm{H}_{1}$ diterima, yang berarti bahwa harga teh internasional berpengaruh signifikan terhadap ekspor teh Indonesia ke Amerika Serikat.

Pada variabel konsumsi teh perkapita Amerika Serikat diketahui bahwa nilai thitungnya adalah sebesar 1.492895 dan t-tabel yang didapat adalah sebesar 1,77. Dengan melihat perbandingan besarnya t-hitung dan t-tabel maka dapat diketahui bahwa t-hitung < ttabel $(2.732038>1,77)$ dengan demikian $\mathrm{H}_{0}$ ditolak dan $\mathrm{H}_{1}$ diterima. Hal tersebut dapat diartikan bahwa konsumsi teh perkapita Amerika Serikat berpengaruh terhadap permintaan ekspor teh Indonesia ke Amerika Serikat.

\section{Analisis Ekonomi}

GDP Amerika Serikat berpengaruh signifikan terhadap nilai ekspor teh Indonesia ke Amerika Serikat selama periode 2000-2017. Signifikannya pengaruh GDP negara tujuan terhadap nilai ekspor the Indonesia sejalan dengan penelitian Sidabalok (2017). Namun hasil penelitian ini berbeda dengan penelitian El Hasanah (2018), yang menemukan tidak signifikannya pengaruh GDP negara tujuan terhadap nilai ekspor the Indonesia.

Koefisien regresi GDP Amerika Serikat sebesar 515.3791. Hal ini berarti apabila GDP Amerika Serikat meningkat 1 Triliun USD, maka nilai ekspor teh Indonesia ke Amerika Serikat meningkat sebesar 515.3791 USD dengan asumsi variabel lainnya konstan/ tetap.

Variabel kurs Rupiah terhadap Dollar Amerika Serikat tidak berpengaruh terhadap nilai ekspor teh Indonesia ke Amerika Serikat selama periode 2000-2017. Hal ini disebabkan karena Amerika Serikat merupakan negara pengkonsumsi teh terbesar di dunia, sehingga jika terjadi apresiasi atau depresiasi kurs Rupiah terhadap Dollar AS tidak akan mempengaruhi permintaan penduduk Amerika terhadap ekspor teh Indonesia. Hal ini konsisten temuan penelitian Qodri (2017), El Hasanah, (2018), dan Monita (2021). Namun demikian temuan 
penelitian ini berbeda dengan temuan Chadir (2017), Sidabalok, (2017) (Mejaya dkk. 2016), (Ginting, 2017) yang menemukan adanya pengaruh negatif dan signifikan antara kurs dan nilai ekspor teh Indonesia.

Harga teh internasional berpengaruh signifikan terhadap nilai ekspor teh Indonesia ke Amerika Serikat selama periode 2000-2017. Hasil tersebut konsisten dengan hasil penelitian yang dilakukan oleh Sidabalok (2017) dan Qodri (2017) dan juga sesuai dengan teori permintaan dalam hukum permintaan dimana semakin tinggi harga ekspor teh di Indonesia maka jumlah permintaan terhadap teh Indonesia akan semakin berkurang, Ceteris Paribus. Koefisien regresi harga teh internasional sebesar -8790.225 , yang berarti apabila harga teh internasional meningkat 1 USD/Ton maka nilai ekspor teh Indonesia ke Amerika Serikat menurun sebesar 8790.225 USD dengan asumsi variabel lainnya konstan/ tetap.

Konsumsi teh perkapita Amerika Serikat berpengaruh signifikan terhadap nilai ekspor teh Indonesia ke Amerika Serikat selama periode 2000-2017. Hal ini konsisten dengan hasil penelitian yang dilakukan oleh Anggraini (2006) yang menyatakan bahwa konsumsi suatu komoditi berpengaruh signifikan terhadap permintaan ekspor komoditi tersebut ke negara tujuan. Koefisien regresi konsumsi teh perkapita Amerika Serikat sebesar 4271546 yang berarti apabila konsumsi teh perkapita Amerika Serikat meningkat $1 \mathrm{Kg} /$ Tahun, maka nilai ekspor teh Indonesia ke Amerika Serikat meningkat sebesar 4271546 USD dengan asumsi variabel lainnya konstan/ tetap.

\section{Implikasi Kebijakan}

Berdasarkan hasil analisis empiris, diperoleh bahwa faktor-faktor yang mempengaruhi permintaan ekspor teh Indonesia ke Amerika Serikat secara signifikan adalah GDP Amerika Serikat, harga teh internasional, dan konsumsi teh perkapita Amerika Serikat, sementara nilai tukar Rupiah terhadap Dollar Amerika Serikat tidak berpengaruh signifikan terhadap permintaan ekspor teh Indonesia ke Amerika Serikat.

Dalam penelitian ini diketahui bahwa nilai ekspor teh Indonesia ke Amerika Serikat senantiasa berfluktuasi setiap tahunnya. Untuk meningkatkan nilai ekspor teh Indonesia ke Amerika Serikat tersebut, dipelukan peran serta pemerintah secara aktif dalam hal peningkatan mutu teh Indonesia agar mampu bersaing dengan negara eksportir lainnya. Sehingga ketika GDP Amerika Serikat meningkat, mereka akan tetap mengimpor teh dari Indonesia bukan dari negara pengekspor teh lainnya. Selain itu, para eksportir teh Indonesia sebaiknya beralih dari teh curah dan mulai menargetkan teh olahan atau teh kemasan yang memiliki nilai tambah yang tinggi dan lebih diminati oleh pihak konsumen.

Pemerintah juga harus berupaya menstabilkan nilai tukar Rupiah terhadap Dollar Amerika Serikat. Hal tersebut dilakukan agar nilai tukar stabil dan dapat mendorong masyarakat maupun pengusaha dalam melakukan kegiatan perdagangan internasional khususnya dalam kegiatan ekspor. Dengan stabilnya nilai tukar maka suatu negara akan memperoleh kepercayaan dari negara lain untuk melakukan kerja sama serta hubungan baik dengan luar neger.

Selain itu juga, pemerintah juga harus berperan secara aktif dalam perkembangan kegiatan ekspor. Adanya kerjasama antara pemerintah dan petani teh dalam upaya meningkatnya kualitas teh harus lebih diperhatikan karena kualitas yang baik akan membuat pihak importir akan meningkatan konsumsinya terhadap teh Indonesia sehingga permintaan terhadap komoditi teh akan meningkat. Yang pada akhirnya walaupun harga teh di pasar internasional meningkat, Amerika Serikat tidak akan mengurangi permintaan terhadap ekspor teh Indonesia. 


\section{Kesimpulan dan Saran}

\section{Kesimpulan}

GDP Amerika Serikat, kurs Rupiah terhadap Dollar Amerika Serikat, harga teh Internasional, dan konsumsi teh perkapita Amerika Serikat berpengaruh sebesar 86,26 persen terhadap nilai ekspor teh Indonesia ke Amerika Serikat, sedangkan sisanya sebesar 13,74 persen dijelaskan oleh faktor lain diluar model. Dari model ini juga didapat variabel GDP Amerika Serikat, harga teh internasional, dan konsumsi teh perkapita Amerika Serikat berpengaruh signifikan terhadap ekspor teh Indonesia ke Amerika Serikat. Sedangkan variabel yang tidak berpengaruh terhadap ekspor teh Indonesia ke Amerika Serikat adalah kurs Rupiah terhadap Dollar AS.

\section{Saran}

Diharapkan ekspor teh Indonesia harus tetap dipertahankan karena secara nyata dapat menghasilkan devisa negara yang dapat digunakan untuk penanggulangan defisit neraca pembayaran, pembayaran hutang luar negeri, maupun pembangunan sarana publik secara nasional yang pada akhirnya dapat menigkatkan kesejahteraan masyarakat. Selain itu, Indonesia harus mampu meningkatkan daya saing teh Indonesia terhadap produk teh negara lain, salah satunya dengan cara meningkatkan kualitas produk ekspor teh Indonesia.

Perlu adanya peran pemerintah secara aktif dalam peningkatan kualitas teh yang akan diekspor ke Amerika Serikat, sehingga ketika GDP AS meningkat, maka mereka akan tetap mengimpor teh dari Indonesia bukan dari negara lain. Selain itu juga, pemerintah harus berupaya dalam mestabilkan harga teh domestik di pasar Internasional, agar negara importir khususnya AS tetap mau mengimpor teh dari Indonesia.

\section{Daftar Pustaka}

Amir, A., Junaidi, J., \& Yulmardi, Y. (2009). Metodologi Penelitian Ekonomi dan penerapannya. IPB Press.

Anggraini, D. (2006). Faktor-faktor yang mempengaruhi permintaan ekspor kopi Indonesia dari Amerika Serikat [Tesis]. Program Pascasarjana Universitas Diponegoro.

Damar, A. D., \& Budiningharto, S. (2011). Analisis faktor-faktor yang mempengaruhi ekspor biji kakao Indonesia ke Malaysia dan Singapura [Skripsi]. Universitas Diponegoro.

Bank Dunia. (2018). Data GDP Amerika Serikat.

Bank Indonesia. (2018). Data Kurs Rupiah terhadap Dollar Amerika Serikat.

Chadhir, M. (2017). Analisis faktor-faktor yang mempengaruhi ekspor teh Iindonesia ke negara Inggris 1979-2012. Economics Development Analysis Journal, 4(3), 292-300. https://doi.org/10.15294/edaj.v4i3.14836

El Hasanah, L. L. N. (2018). Analisis Faktor Yang Mempengaruhi Volume Ekspor The Indonesia Ke Jerman (Tahun 1990-2015). [Skripsi). Universitas Islam Indonesia

Food and Agriculture Organization. (2018) . Data Konsumsi Teh Perkapita Amerika Serikat.

Ginting, A. M. (2017). Analisis Pengaruh Ekspor Terhadap Pertumbuhan Ekonomi Indonesia. Buletin Ilmiah Litbang Perdagangan, 11(1), 1-20.

Hasanah, S. I. (2017). Determinan Ekspor Komoditi Pinang di Provinsi Jambi [Skripsi]. Prodi Ekonomi Pembangunan Fakultas Ekonomi dan Bisnis Universitas Jambi.

Kementrian Keuangan - Direktorat Jendral Bea dan Cukai. (2018) . Data Nilai Ekspor Teh Indonesia ke Amerika Serikat.

Mejaya, A. S., Fanani, D., \& Mawardi, M. K. (2016). Pengaruh Produksi, Harga Internasional, Dan Nilai Tukar Terhadap Volume Ekspor (Studi Pada Ekspor Global Teh Indonesia Periode Tahun 2010-2013). Jurnal Administrasi Bisnis, 35(2), 20-29. 
Monita, R., \& Hasmarini, I. M. I. (2021). Analisis Faktor-Faktor Yang Mempengaruhi Ekspor Teh Indonesia Ke Malaysia Tahun 1984-2018. [Skripsi]. Universitas Muhammadiyah Surakarta. 